Faculdade

de Ciências Econômicas UFRGS
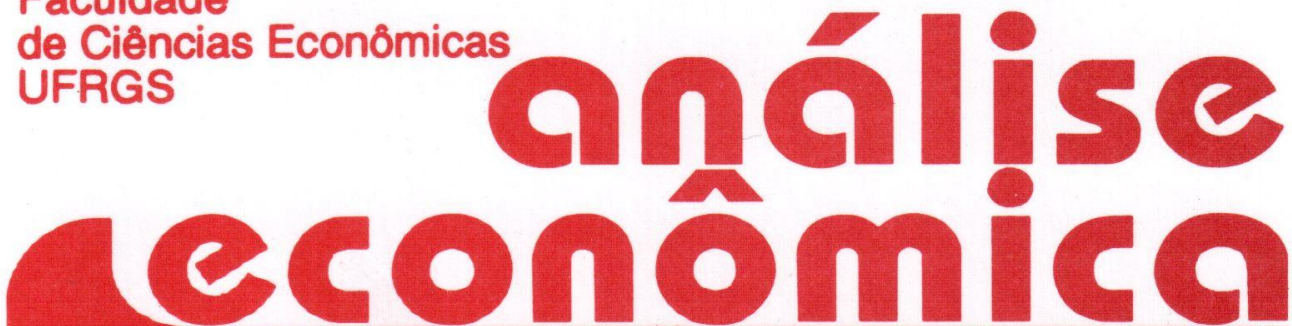

- globalização, Blocos REgIONAIS E O SETOR AGRÍ́COLA NO MERCOSUL Paulo D. Waquil

- globalização: ReALIdAde E UTOPIA

Gentil Corazza

- DO FOREIGN CURRENCY DEPOSITS DID THEY IMPROVE WELFARE?

Carlos A. Janada

- MACROECONOMIC INSTABILITY AND STRATEGIES OF TRANSNATIONAL CORPORATIONS IN BRAZIL

Reinaldo Gonçalves

- INFRASTRUCTURE, PUBLIC CAPITAL AND GROWTH IN THE BRAZILIAN ECONOMY

Stefano Florissi

+ EFEITOS DO PLANO REAL SOBRE O RIO GRANDE DO SUL Marcelo S. Portugal

- REgIONALIZAÇÃo dA MATRIZ dE INSUMO-PRODUTO E O IMPACTO DO AUMENTO DA PRODUÇÃO DE GRÃOS NO RS E NO BRASIL

Nali de Jesus de Souza

- IMPORTACõES DE LEITE E A PECUÁRIÁ LEITEIRA NO BRASIL Silvinha P. Vasconcelos

- ANPEC: CURSO PREPARATÓRIO

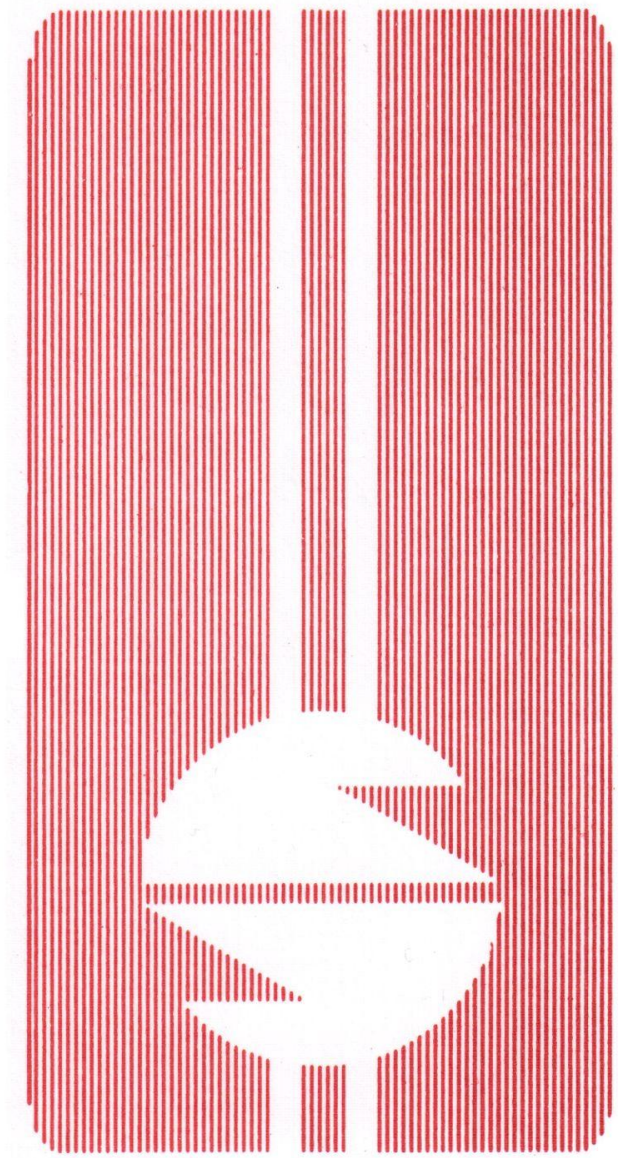


UNIVERSIDADE FEDERAL DO RIO GRANDE DO SUL

Reitor. Prof ${ }^{a}$. Wrana Maria Panizzi

FACULDADE DE CIÊNCIAS ECONÔMICAS

Diretor. Prof'. Otília Beatriz Kroeff Carrion

CENTRO DE ESTUDOS E PEQUISAS ECONÔMICAS

Diretor: Prof. Paulo Alexandre Spohr

DEPARTAMENTO DE CIÊNCIAS ECONÔMICAS

Chefe: Prof. Gentil Corazza

CURSO DE PÓS-GRADUAÇÃO EM ECONOMIA

Coordenador. Prof. Marcelo Savino Portugal

CURSO DE PÓS-GRADUAÇÃO EM ECONOMIA RURAL.

Coordenador. Prof. Carlos Guilherme A. Mielitz Netto

CONSELHO EDITORIAL: Achyles Barcelos da Costa, Aray Miguel Feldens, Carlos Augusto Crusius, Carlos Guilherme A. Mielitz Netto, Eugênio Lagemann, Fernando Ferrari Filho, Gentil Corazza, Marcelo Savino Portugal, Nali de Jesus de Souza, Otília Beatriz K. Carrion, Paulo Alexandre Spohr, Paulo Dabdab Waquil, Pedro Cezar Dutra Fonseca, Roberto Camps Moraes, Valter José Stülp, David Garlow (Wharton Econometrics Forecasts Association, E.U.A.), Edgar Augusto Lanzer (UFSC), Eleutério F. S. Prado (USP), Fernando de Holanda Barbosa (FGV/RJ), Gustavo Franco (PUC/RJ), João Rogério Sanson (UFSC), Joaquim Pinto de Andrade (UnB), Juan H. Moldau (USP), Werner Baer (Univ. de Illinois, E.U.A.).

COMISSÃO EDITORIAL: Fernando Ferrari Filho, Gentil Corazza, Paulo Dabdab Waquil, Marcelo Savino Portugal, Roberto Camps Moraes.

EDITOR: Nali de Jesus de Souza

SECRETARIA: Cláudia Porto Silveira, Jeferson Luis Bittencourt. Revisão de textos: Vanete Ricachescki.

FUNDADOR: Prof. Antônio Carlos Santos Rosa

Os materiais publicados na revista Análise Econômica são da exclusiva responsabilidade dos autores. É permitida a reprodução total ou parcial dos trabalhos, desde que seja citada a fonte. Aceita-se permuta com revistas congêneres. Aceitam-se, também, livros para divulgação, elaboração de resenhas e recensões. Toda correspondência, material para publicação (vide normas na terceira capa), assinaturas e permutas devem ser dirigidos ao seguinte destinatário:

PROF. NALI DE JESUS DE SOUZA

Revista Análise Econômica

Av. João Pessoa, 52

CEP 90040-000 PORTO ALEGRE - RS, BRASIL

Telefones: (051) 316-3348 e 316-3440

Fax: (051) 225-1067 


\section{AS IMPORTAÇÕES DE LEITE E OS REFLEXOS SOBRE O DESENVOLVIMENTO DA PECUÁRIA LEITEIRA NO BRASIL*}

Silvinha P. Vasconcelos

\section{SINOPSE}

A pecuária leiteira tem apresentado crescimento insuficiente da oferta, levando a constantes importações de produtos lácteos, muitas vezes subsidiados na origem, como forma de minimizar as crises de abastecimento interno nos períodos críticos de entressafra e nos periodos de ganhos de renda real per capita. Estas importações dão origem a uma nova preocupação com o desenvolvimento do setor leiteiro, pois representam um desestímulo ao produtor na decisão de aumentar a produção e romper com o padrão extrativo da atividade. Neste contexto, este estudo objetivou avaliar os possiveis fatores que influenciam ou podem determinar o fluxo de importações de leite e seus efeitos sobre o setor leiteiro no Brasil, dentro de contextos domésticos e internacionais.

\section{INTRODUÇÃO}

O mercado internacional de produtos agricolas vem, ao longo dos anos, sinalizando para um novo movimento dos fluxos de comércio, em que os países em desenvolvimento perdem suas antigas relações preferenciais e os países desenvolvidos se tornam cada vez mais exportadores destes produtos (Coutinho, 1994). Isto significa que os paises em desenvolvimento são cada vez mais importadores de alimentos, pois sua participação na demanda mundial de produtos agrícolas tem aumentado significativamente ao longo dos anos (Tubiana, 1985).

Pode-se dizer que esta nova dinâmica dos fluxos de comércio dos produtos agrícolas surge em função de dois aspectos básicos: por um lado, cada vez mais os países subdesenvolvidos se deparam com déficits na disponibilidade interna de alimentos. Isto, em parte, pode ser atribuído ao padrão de desenvolvimento agricola adotado, que priorizou o cultivo de produtos agrícolas voltados basicamente para exportação em detrimento das culturas de mercado

\footnotetext{
"Elaborado com base na dissertação de mestrado "Demanda por importação de leite no periodo de 1960 a 1994 e desenvolvimento do setor leiteiro no Brasil", defendida em 1995, no Curso de PósGraduação em Economia Rural da UFRGS.

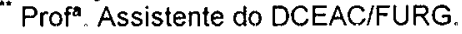

\begin{tabular}{|c|l|}
\hline $\begin{array}{c}\text { Cód. AEA } \\
718\end{array}$ & $\begin{array}{l}\text { Palavras-chave: fluxos de comércio, setor leiteiro brasileiro, } \\
\text { politica agricolas internacionais. }\end{array}$ \\
\hline
\end{tabular}

\begin{tabular}{|l|l|l|l|}
\hline ANÁLISE ECONÔMICA & ANO 15 & Março/97 & p. 130-153 \\
\hline
\end{tabular}


interno (Rezende, 1983). Por outro lado, os países desenvolvidos possuem um superávit produtivo na agricultura, o que desencadeou uma política visando o escoamento da produção excedente e a conquista de mercados para seus produtos, contribuindo para o novo movimento internacional no comércio de produtos agrícolas.

No caso do mercado mundial de produtos lácteos, o novo fluxo de comércio que direciona produtos agrícolas dos países desenvolvidos para os subdesenvolvidos, também pode ser observado. Cada vez mais, os maiores produtores mundiais de leite de vaca, são também maiores exportadores. $E$, cada vez mais, paises como o Brasil necessitam importar este alimento. De acordo com o Departamento de Agricultura dos Estados Unidos (USDA), apud Bortoleto (1992), os maiores produtores são, em ordem decrescente: a Comunidade Econômica Européia (CEE); a Ex-União Soviética; e Estados Unidos (EUA). E entre os maiores importadores de leite em pó, nos últimos anos, estão o México, Japão e Brasil .

Contudo, apesar de os maiores produtores estarem em situação privilegiada ao alcançar relativa auto-suficiência na produção de leite, o volume excedente se tornou um problema de desequilibrio de mercado. Em outros termos, isto significa que o consumo mundial tem evoluido menos que a produção mundial, segundo Silva (1993).

Por este motivo, alguns paises adotaram politicas no sentido de diminuir os estoques, via redução de produção e/ou escoamento do produto para o mercado internacional. Nos EUA e na CEE, que estão entre os maiores exportadores, foram implementadas medidas no sentido de adequar demanda e oferta. Tanto os EUA quanto a CEE, a qual estabeleceu cotas de produção entre seus paises membros, buscaram frear a expansão mundial de leite e derivados, segundo Carfantan (1993a). Entretanto, apesar de alguns resultados em termos de contração da oferta estarem sendo alcançados com a redução do número de vacas em lactação, houve ganhos de produtividade, que tornaram constantes os altos niveis de produção (Bortoleto1992).

Como há uma dificuldade histórica e estrutural do Brasil ao atendimento da demanda por parte da produção interna de leite (Farina, 1990), enquanto nos países desenvolvidos não há absorção de toda sua produção, os excedentes destes últimos acabam sendo direcionados para países que possuem déficits produtivos.

As tendências no movimento mundial do comércio dos produtos agrícolas indicam, então, que os países subdesenvolvidos estão cada vez mais dependentes dos rumos que os paises desenvolvidos dão aos seus setores agricolas, mesmo porque os primeiros não têm a gama de recursos necessários 
para reverter este quadro.'

Então, vislumbra-se um cenário mundial diferente no longo prazo, que certamente deve efetivar novos padrões nos fluxos de comércio e aumentar a dependência de certos países em desenvolvimento, que, além de financeira e tecnológica, também pode vir a ser alimentar.

O Brasil certamente não se encontra situado nesta posição limite, porque nos últimos anos a agricultura vem respondendo ao mercado interno de forma relativamente satisfatória. Mas algumas atividades dentro do setor agricola ainda não se desenvolveram de forma a ofertar o minimo recomendado pelos órgãos de saúde, como é o caso do setor leiteiro. Em outros termos, a pecuária leiteira tem apresentado crescimento insuficiente da oferta, dentro dos padrões nutricionais recomendados a nivel mundial, e seu perfil produtivo atual não indica um setor moderno como um todo, capaz de realizar ganhos produtivos significativos. Pelo contrário, o Brasil tem se caracterizado por importar produtos lácteos, muitas vezes subsidiados na origem, como forma de minimizar as crises de abastecimento interno nos períodos críticos de entressafra e nos períodos de ganhos de renda real per capita.

Neste contexto, as importações dão origem a uma nova preocupação, pois são, na verdade, uma demanda negativa, ou seja, uma demanda que deixa de se realizar internamente. Portanto, os estímulos de uma maior demanda atendida por importações são repassados para o produtor estrangeiro em detrimento do produtor interno.

Se, somente o crescimento vegetativo da demanda por alimentos, desencadeou constantes importações por leite e derivados no passado, então, uma possivel retomada de crescimento econômico poderia efetivar a demanda potencial por lácteos, piorar o quadro de abastecimento interno destes produtos e pressionar uma repentina expansão das importações, formando um círculo vicioso.

Em suma, o padrão atual do comércio mundial de produtos agrícolas impõe um novo fluxo, que é o escoamento de excedentes para países com déficits produtivos. Considerando esta premissa, este artigo visa analisar quais são as perspectivas para o movimento futuro da demanda por importações de leite e os seus possiveis efeitos sobre o desempenho do setor leiteiro no Brasil.

Para atender à este objetivo, será feita uma breve referência ao perfil atual da atividade leiteira no Brasil frente a grandes produtores mundiais, no tópico 2. Posteriormente, no tópico 3 , serão traçados alguns cenários que podem

\footnotetext{
1 Entretanto, os maiores produtores mundiais têm apresentado limitações orçamentárias, que podem levar à redução dos gastos com a proteção ao setor agricola. Por outro lado, a permanência da política de estímulo à este setor nos últimos anos provocou modernização tecnológica e ganhos produtivos que não são facilmente reversíveis. Assim, a redução no volume de recursos destinados à proteção não significa que esta última deva deixar de existir totalmente.
} 
influenciar o fluxo de importações internas de leite. E, por último, no tópico 4, serão considerados os multiplicadores da renda, produto e emprego do setor leiteiro como uma proxy indicadora dos efeitos destas importações sobre o desenvolvimento da pecuária leiteira no Brasil.

\section{O PERFIL DO SETOR LEITEIRO NO BRASIL FRENTE AOS GRANDES PRODUTORES MUNDIAIS}

\subsection{Perfil do mercado interno}

\subsubsection{Caracteristicas do segmento consumidor de leite}

Apesar da importância nutricional do leite, no Brasil, seu consumo é muito baixo quando comparado ao consumo dos paises mais desenvolvidos, pois a disponibilidade habitante/dia é inferior à quantidade mínima recomendada pelos órgãos de saúde nacionais e internacionais (Mendes, 1990).

Mas a constatação do motivo que leva ao reduzido consumo com base somente na insuficiência relativa de disponibilidade per capita de leite no Brasil é parcial. Pois o baixo consumo pode ser explicado, inclusive, a partir do declínio da massa real dos salários e da intensificação da concentração de renda, que comprometeram o poder de compra da população e geraram uma demanda potencial reprimida pelo produto. ${ }^{2}$ Dados da FAO - Food and Agriculture Organization (1994), confirmam os problemas que os desequilibrios na distribuição de riqueza no Brasil geram em torno do consumo de calorias, pois $67 \%$ da população consome menos do que a média mínima de 2.400 calorias diárias recomendadas pela FAO e pela Organização Mundial de Saúde.

Com o ubjetivo de atender ao segmento de classe com renda mais elevada, a indústria laticinista, por sua vez, realiza uma demanda intermediária e transforma o leite "in natura" em produtos derivados. Como forma de ampliar o universo de consumidores e contornar o problema da demanda reprimida por leite, um mecanismo utilizado pelas indústrias brasileiras de laticinios é o de lançar produtos mais elaborados e diversificados, ${ }^{3}$ que são absorvidos em geral pelo segmento de maior poder aquisitivo, conforme Mendes (1990).

Assim, dada a maior concorrência com as indústrias de paises tradicionais

\footnotetext{
2 Para comprovar a existência da demanda potencial reprimida por leite, tem-se os resultados alcançados por Mendes (1990), que revelam o leite, no Brasil, como um bem superior, dado que a elasticidade-renda da demanda pelo produto è de 1,26. Isto significa que variações na renda de $10 \%$ provocariam variações na demanda de $12,6 \%$, ou seja, aumentos mais do que proporcionais no consumo de leite.

3 Não só na indústria laticinista brasileira esta tendência de diversificação se verifica. Conforme Soares (1995), a iniciativa de uma indústria argentina especializada ern produtos lácteos, com o intuito de competir no mercado brasileiro de leite, levou à fabricação, após oito anos de pesquisa, de leite longa vida contendo ferro, sem qualquer alteração na cor ou sabor do produto
} 
na produção de lácteos, a indústria laticinista brasileira tende a se utilizar cada vez mais do artifício de diversificação de produtos, para não perder ou reduzir sua fatia no mercado. Conseqüentemente, o mercado-alvo visado pelas indústrias de laticinios no Brasil tende a permanecer equivalente àqueles segmentos de renda mais elevados, capazes de absorver preços maiores condizentes com os investimentos passiveis de serem realizados no setor.

\subsubsection{Caracteristicas do segmento produtor de leite}

No Brasil, a pecuária leiteira representa $9 \%$ do PIB da agropecuária nacional (Bortoleto e Wedekin, 1990), mas tem se deparado com substanciais barreiras, posto que a atividade tem apresentado um crescimento insuficiente da oferta nos últimos anos (Gomes et alii, 1989).

$\mathrm{Na}$ exploração da atividade leiteira, de acordo com Bortoleto e Wedekin (1990) e Araújo (1994) predomina a existência de um grande número de pequenos produtores (vendem até 100 litros de leite/dia), mas o maior volume da produção provém dos grandes produtores (vendem mais de 100 litros de leite/dia)

Apesar de os grandes produtores serem responsáveis por maior parte da produção e o Brasil possuir o segundo maior rebanho bovino do mundo, a produtividade do rebanho leiteiro nacional é baixa frente à média mundial. Dados da FAO (1993) mostram que em paises desenvolvidos como EUA, Dinamarca, Canadá, Japão, Holanda e Finlândia, a produtividade é, na média, em torno de $5.850 \mathrm{~kg} /$ animal/lactação. Na Argentina, a produtividade é de $2.200 \mathrm{~kg} /$ animal/lactação quase o mesmo patamar de países como a França, Polônia e ex-URSS. O Brasil, no entanto, tem produtividade de 769

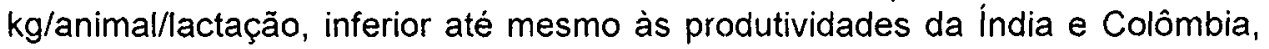
que são de 793 e $930 \mathrm{~kg} /$ animal/lactação, respectivamente.

Sob estas condições, atualmente, a atividade leiteira no Brasil proporciona uma baixa produção per capita do produto, em torno de 98 litros/pessoa/ano, frente aos 215 litros/pessoa/ano, recomendado pela FAO (Martins, 1992).

O rebanho utilizado na atividade leiteira do Brasil está composto por animais de raças indianas de corte, de raças européias de leite e de animais de dupla aptidão (carne e leite). Estas características genotípicas geram uma estreita relação entre os mercados de leite e carne, não havendo, portanto, uma pecuária especializada, segundo Bortoleto e Wedekin, (1990), Farina (1990) e Reis et alii (1993).

Farina (1990) faz considerações de extrema importância na análise das conseqüências resultantes da existência de um o efetivo leiteiro nacional não especializado ou de dupla aptidão (carne/leite). Segundo a autora, este aspecto traz consigo problemas (estruturais) de oscilações na oferta de leite devido à 
sazonalidade, à influência do preço do boi gordo e ao nivel de produtividade.

No que se refere à sazonalidade, na medida em que o leite não é a atividade principal, a produção é proporcionalmente variável ao volume de pastagens disponiveis. Desta forma, como afirma Mueller (1987), a maior produção se concentra no período das águas (ou estação das chuvas) em São Paulo, Minas Gerais e Centro-Oeste, e no verão no Sul do país, quando se fornece aos rebanhos melhor alimentação.

A não-especialização do rebanho se traduz também na sensibilidade da oferta de leite em relação aos preços da arroba do boi para abate, o que significa que as instabilidades do mercado de carne são repassadas para o de leite. Conforme Mascolo (1980), quando a relação dos preços favorece a criação, há uma redução da oferta de leite, com o intuito de alimentar os bezerros. Já na reversão do ciclo do gado, ${ }^{4}$ quando a relação de preços favorece a produção leiteira, os pecuaristas se desfazem dos bezerros, o que eleva a oferta de leite em um primeiro momento. Posteriormente, quando o preço do boi atinge um mínimo, o desestímulo à criação leva ao abate de matrizes e a oferta de leite se reduz.

Outra conseqüência da não-especialização do rebanho leiteiro nacional, segundo Farina (1990), é a baixa produtividade como um todo, revelando a predominância de produtores que exploram a atividade de forma tradicional.

Então, a baixa produtividade, os rebanhos não selecionados e a sazonalidade da produção afetam a rentabilidade dos produtores leiteiros e entravam o desenvolvimento do setor no Brasil. Por agravante, estes obstáculos são mais difíceis de serem transpostos por existir uma estrutura de demanda final e intermediária incompativel com tal fim.

Ao mesmo tempo em que se constata a existência destas barreiras ao crescimento da oferta leiteira, o principal instrumento de política para o setor - o controle de preços vigente até 1990 - não estimulou, conforme Martins (1992), um maior aumento da produção, durante o periodo de sua implementação.

\subsubsection{Características dos principais produtores mundiais de leite}

Nos países do Mercosul, mais especificamente, na Argentina e Uruguai, a produção de leite não passa pelos mesmos problemas ocorridos no Brasil. Nestes paises, há superávit de produção e os produtos lácteos participam ativamente da pauta de exportações. Além disso, seus altos índices de produtividade decorrem basicamente das vantagens em termos de clima mais

\footnotetext{
${ }^{4}$ A origem do ciclo do gado está na resposta defasada da produção de bovinos às mudanças nas condições de mercado, segundo Mueller (1987). Mas, atualmente, a produção de bovinos tem um componente a mais que é a mudança na evolução da produção de carnes em geral, devido mais ao crescimento vertiginoso do mercado de carne de frango (Pinazza e Moura, 1996).
} 
temperado, de solo mais fértil ou de relevo mais plano.

O privilégio natural que estes países possuem reduz significativamente o custo de produção de leite. Outro aspecto que marca a vantagem comparativa de produção frente ao Brasil, está no acesso a alguns insumos agropecuários relativamente mais baratos, como ração concentrada, ordenhadeiras e adubo (Dias, 1990).

A atividade leiteira argentina, de acordo com Lopes e Jank (1992), representa cerca de $6 \%$ do seu PIB agropecuário, participa com $1,25 \%$ na produção mundial de leite e $20,17 \%$ do montante da América do Sul, tendo 800 indústrias leiteiras, que empregam 30 mil pessoas. Mas, segundo os mesmos autores, apenas duas grandes companhias, que possuem $40 \%$ da captação de leite, controlam o mercado interno de leite e derivados. São a Sancor Cooperativas Unidas Ltda (Sancor) e a Mastellone Irmãos S/A (La Serenissima) ${ }^{5}$

Segundo Zylbersztajn \& Farina (1991), apesar de o excedente argentino de 1,5 bilhões de litros de leite/ano não ser suficiente para suprir déficits produtivos brasileiros, qualquer internalização de produtos deste país pode pressionar fortemente o mercado interno à nivel regional, principalmente no periodo da safra.

A dinâmica da indústria láctea uruguaia, a exemplo da indústria argentina, também se encontra atrelada ao mercado externo, sendo que qualquer retração econômica nos seus parceiros comerciais reflete sobre os preços internos do leite. De toda a produção leiteira uruguaia, parte significativa é exportada. Somente em 1989, foram exportados, segundo Dias (1990), cerca de 40.000 toneladas de produtos lácteos.

Os Estados Unidos, também pais tradicionalmente fornecedor de leite e derivados e um dos maiores produtores, tem, conforme Dias (1992), nas regiões norte e nordeste, as bacias leiteiras mais tradicionais. De acordo com este autor, o estado de Wisconsin é o maior produtor e tem o maior número de

\footnotetext{
${ }^{5}$ A importancia dos mercados externos para estas empresas é evidente, pois, segundo Dias (1990), a exportação da Sancor, por exemplo, correspondeu, em 1989, a $20 \%$ de seu faturamento global, alcançando então, cerca de 61 milhões de dólares, sendo o Brasil um de seus grandes clientes. Por outro lado, a empresa La Sereníssima exportou um total de 16 mil toneladas de leite e manteiga em 1989 , sendo que $76 \%$ deste total se destinou ao Brasil (Dias, 1990). A participação da Argentina como fornecedor de lácteos para o Brasil vem crescendo vertiginosamente, sendo que somente entre 1988 e 1989, as importações brasileiras de lácteos provenientes daquele país se elevaram 10 vezes, conforme Jank (1992)

${ }^{6}$ A Cooperativa Nacional de Produtores de Leite (CONAPROLE), conforme Dias (1993), recebe $80 \%$ do leite remetido para industrialização e participa com mais de $90 \%$ das exportações de lácteos uruguaios, sendo o Brasil seu maior comprador. De acordo com este autor, até 1974, o leite uruguaio destinava-se basicamente ao abastecimento interno, sendo a CONAPROLE a grande responsável pela abertura ao mercado externo desde então.
} 
vacas, cerca de 1,7 milhão de cabeças, somente de raças especializadas. A Califórnia é o segundo estado produtor no pais, sendo que as fazendas nesta região chegam a produzir mais de 100 mil litros de leite por dia.

Mas, segundo o mesmo autor, a Flórida, apesar de não ser um estado tradicionalmente produtor, vem despontando no país, devido aos melhores preços relativos que vem auferindo $(0,33$ cents/litro frente aos 0,24 cents/litro no norte) e às maiores produtividades relativas que vêm alcançando.

Apesar de ocorrerem algumas diferenças regionais, os Estados Unidos têm hegemonia na produção leiteira frente aos demais produtores (considerando os países da Comunidade Econômica Européia isoladamente), o que pode ser confirmado na medida em que exportam volumes significativos de leite em pó (em torno de 114 mil toneladas em 1993) (Estatísticas Lácteas, 1989).

Os níveis produtivos alcançados pela pecuária leiteira americana contam ainda com uma maciça intervenção protecionista, com base em três raios de ação, que são, segundo Carley (1993), os planos de preços minimos, controles da oferta e estímulos às exportações dos volumes excedentes, além da existência de organizações engajadas na defesa do setor leiteiro, que são em torno de quatorze, como acrescenta Bocher, (1993).

A Comunidade Econômica Européia (CEE), por sua vez, è a maior região produtora de leite no mundo, respondendo por $25 \%$ da oferta mundial do produto, cerca de 113 bilhões de litros em 1992 e por quase a metade das exportações de derivados (FAO, 1993).

Também internamente a pecuária leiteira se sobressai, pois esta atividade é responsável por cerca de um quinto do valor da produção agrícola da CEE e tem alcançado excedentes produtivos internos (como $34 \%$ para a manteiga e $34 \%$ para o leite em pó desnatado), de acordo com Carfantan (1993b). Dado o peso relativo substancial que a região européia apresenta frente ao mercado global, alterações internas têm amplas repercussões nos preços e nos volumes transacionados nos mercados leiteiros mundiais.

Burtin (1988) considera que, apesar de possuir um rebanho leiteiro em torno de 10 milhões de cabeças, a média de animais por fazenda leiteira é relativamente pequena (16 cabeças), se comparada à média americana (75 cabeças), pois a agricultura européia apresenta um grande número de pequenos produtores. E o desempenho destes produtores é significativamente afetado pela Política Agricola Comum, pois, de todos os recursos destinados ao setor agrícola da CEE, a maior parte, ainda segundo Burtin (1988) se destina às despesas de suporte e subsídios ao leite.

A busca da CEE por ganhos de produtividade levou a crescimentos geométricos na produção de leite da região, mas a continuidade deste movimento ascendente na oferta vem sendo desestimulada ao longo dos anos. 
Para Beasley e Neff (1992), os mecanismos utilizados para enfrentar os desequilibrios entre oferta e demanda foram a redução dos rebanhos e do volume de entrega. ${ }^{7}$ Mas, segundo os autores, estas políticas não se mostraram eficazes, pois, em 1983, a auto-suficiência leiteira da CEE alcançou $130 \%$, gerando pesados encargos na manutenção dos estoques crescentes. Por este motivo, em 1984/85, a CEE chegou a implementar cotas de produção entre os países membros e uma penalidade de $115 \%$ do preço do leite, que seria aplicada aos produtores que ultrapassassem o limite estabelecido.

\section{ALGUNS CENÁRIOS E PERSPECTIVAS INTERNAS E INTERNACIONAIS PARA O SETOR LEITEIRO NO BRASIL}

\subsection{Direcionamento das políticas agricolas da CEE e dos EUA e reflexos sobre o setor leiteiro no Brasil}

Apesar da agricultura representar parcela modesta das exportações e do emprego nas principais economias desenvolvidas, e uma parcela menor ainda do PIB, segundo Abreu e Loyo (1994), há justificativas para a manutenção das políticas agricolas protecionistas, basicamente porque há $\circ$ interesse em manter uma auto-suficiência alimentar com uma estabilidade da oferta e alargamento dos mercados.

A Política Agrícola Comum da CEE merece destaque devido à posição que, de acordo com Becker (1994), este bloco comercial consegue manter no comércio agrícola mundial, de maior importador e segundo maior exportador. ${ }^{8}$

Como foi mencionado, no setor de lácteos, a política protecionista da CEE tem sido muito intensa. Conforme Burtin (1988), a CEE destinava em média, de 1983 a 1985, parte significativa do seu Fundo de Orientação e Garantia Agrícola, cerca de $29,3 \%$, para a pecuária leiteira. Assim, o setor leiteiro, para este autor, se revelou aquele de maior apoio comunitário, com quase um terço das despesas totais de garantia à renda agricola.

Enquanto instrumento de estabilização dos mercados internos e de garantia de oferta de alimentos, a Politica Agrícola Comum da CEE alcançou êxito. Entretanto, dois problemas se verificam atualmente. Por um lado, há uma dificuldade de manutenção desta política, devido à pressão orçamentária crescente. Segundo Becker (1994), as despesas orçamentárias da CEE, com o fundo europeu orientado para a garantia de rendas agrícolas, totalizaram mais

\footnotetext{
${ }^{7}$ Os produtores eram pagos para não entregar leite num prazo determinado, ou para transformar seu gado leiteiro em gado de corte.

8 Dentre os resultados alcançados pela PAC tem-se que, nos anos 60 (quando ainda não havia se consolidado o Mercado Comum na Europa), o nível de auto-suficiência estava, segundo Becker (1994) abaixo de $100 \%$ em todos os produtos alimenticios, $e$, no final dos anos 80 , este nivel superou os $100 \%$.
} 
da metade do orçamento global em 1989 , cerca de $59,6 \%$.

Além dos problemas orçamentários que a PAC traz consigo, sua implementação contribuiu para desestabilizar o mercado mundial. Em função disto, a tendência para os próximos anos é a reformulação de suas diretrizes, posto que a CEE se comprometeu em reduzir o volume de exportações subsidiadas, sendo que, de acordo com Becker (1994), projetam-se maiores reduções no volume de exportações subsidiadas de leite em pó desnatado, que devem cair em torno de $70 \%$, seguindo a redução de cerca de $35 \%$ no volume das exportações subsidiadas de queijo e, de outros laticinios, em torno de $25 \%$.

Assim como na CEE, a política agrícola norte-americana tem por objetivo manter niveis de preço e renda internos, aliada à meta de conquistar maiores fatias do mercado agrícola internacional. Contudo, como o que vem ocorrendo na $\mathrm{CEE}$ ao longo dos últimos anos, o apoio prestado aos produtores pelo governo dos EUA tem declinado, devido à redução de recursos. De acordo com Langley (1994), os equivalentes de subsídios ao produtor (PSE), em 1986, giravam em torno de $34 \%$ da renda total do produtor, mas em 1991 passaram para $19 \%{ }^{9}$

Entretanto, no setor de laticínios da CEE ou dos EUA há uma substantiva politica de suporte à renda do produtor, dado que, conforme Coutinho (1994), o subsídio ao produtor na CEE e nos EUA corresponde a $31,7 \%$ e a $23,4 \%$ dos valores da produção, respectivamente, enquanto no Brasil não há subsídio algum.

Mas, com as dificuldades na manutenção destas políticas de sustentação da renda agrícola, há uma tendência de liberalização do comércio agrícola dos EUA e da CEE, o que geraria efeitos sobre o setor leiteiro no Brasil, considerando que os mesmos são os paises que mais tendem a influir no mercado mundial do produto.

Simulações feitas por Coutinho (1994), indicam que uma liberalização total da agricultura dos EUA acarretaria mudanças mais significativas nos preços mundiais dos laticínios, em relação aos outros produtos agricolas. Isto não surpreende na medida em que os laticinios recebem os maiores subsídios em relação aos demais produtos agrícolas considerados. Segundo este mesmo autor, a maior elevação do preço mundial, no grupo de laticinios, seria do queijo, cerca de $18 \%$.

Conseqüentemente, o aumento dos preços mundiais de laticínios poderia

9 O PSE representa a estimativa dos subsídios ao produto decorrentes de várias medidas governamentais, como de suporte à renda, intervenção no preço, subsidios aos insumos e assistência à comercialização. Assim, o PSE estima o valor das transferências recebidas pelos produtores e a razão entre o valor total da transferência ao produtor e a renda total do produtor agrícola (Langley, 1994) 
desencadear uma alta dos preços dos lácteos no Brasil. O maior impacto da liberalização total dos EUA sobre os preços agricolas no Brasil ocorreria sobre os preços dos derivados de leite e do leite in natura, sendo que neste grupo, a liberalização dos preços do queijo seria responsável pela maior variação no preço pago ao produtor, de $8,7 \%$, seguido pelo leite em pó, que ocasionaria uma elevação no preço pago ao produtor, de 6,7\% (Coutinho, 1994). Neste caso, o que se pode inferir, é que o aumento dos preços mundiais decorrente da retirada do protecionismo dos EUA não repercutiria significativamente no mercado mundial e brasileiro de produtos lácteos.

Já os efeitos de uma liberalização completa do protecionismo da CEE sobre os preços mundiais seriam o aumento substancial destes, de cerca de $46 \%$ para a manteiga e o queijo, e de $21 \%$ para leite em pó, segundo Coutinho (1994). Estes aumentos de preços se explicam pelo fato de a Europa dar altos niveis de assistência exatamente a estes produtos e ser responsável por parte significativa do comércio mundial. Os resultados atingidos reforçam o argumento de que o protecionismo europeu em muito contribui para deprimir os preços dos lácteos no mercado internacional.

Enquanto os preços aos produtores europeus tendem a cair com a supressão das políticas protecionistas, o Brasil teria uma alta nos preços dos lácteos, em conseqüência da alta dos preços internacionais. Segundo Coutinho (1994), os preços da manteiga e do queijo experimentariam uma alta de cerca de $21 \%$, enquanto o preço do leite em pó subiria em torno de $10 \%$.

Os resultados encontrados pelo autor mostram, então, que o complexo agroindustrial do leite no Brasil está perdendo de alguma forma com a manutenção das políticas de suporte à agricultura pelos EUA e pela CEE. Nos dois casos, com a liberalização, os preços mundiais dos laticínios e o efeito de transmissão de preços levaria a maiores preços pagos aos produtores brasileiros de leite e derivados.

Os resultados mostram também que os efeitos sobre a produção interna de lácteos seriam mais significativos com a liberalização da políticas protecionistas da CEE. Pode-se ainda inferir acerca dos efeitos sobre o setor leiteiro no Brasil a partir de dois ângulos de visão. Primeiro, a alta nos preços internacionais poderia estimular tradicionais produtores mundiais (como Argentina e Uruguai, por exemplo) a aumentar a participação no mercado externo e reforçar a tendência importadora de paises tradicionalmente deficitários (como ○ Brasil, por exemplo). Por outro lado, uma segunda hipótese seria a de que maiores estímulos decorrentes de aumentos nos preços mundiais poderiam inverter a posição de importadores para exportadores de laticínios, devido ao efeito transmissão de aumentos dos preços externos aos preços internos. Esta inversão iria depender, no caso brasileiro, pelo menos da conjugação de outras 
variáveis, como estímulo à superação de barreiras internas. Considerando as variáveis que historicamente têm determinado a atividade no Brasil, fica difícil de imaginar a confirmação da segunda hipótese.

\subsection{Perspectivas com a integração econômica do Mercosul}

Outro cenário importante a ser considerado na análise das tendências do mercado leiteiro seria a perspectiva de integração econômica no Mercosul. As assimetrias existentes entre a atividade leiteira brasileira, argentina e uruguaia (principais produtores do Mercosul), que se traduzem em diferenças nas eficiências técnicas e econômicas, tendem a repercutir negativamente no desenvolvimento do setor leiteiro interno, pois a atividade leiteira, no Brasil, apresenta maiores custos relativos de produção e menores niveis de produtividade, conforme Dias (1990).

A análise da competitividade do setor leiteiro do Brasil frente ao Mercosul foi realizada por Araújo (1994), utilizando como pais representativo do potencial competitivo da região, a Argentina, ${ }^{10}$ em confronto com Minas Gerais, estado maior produtor no Brasil.

Em um primeiro momento, ${ }^{11}$ o leite em pó desnatado advindo do Mercosul seria mais barato $e$, portanto, mais competitivo, apenas em relação ao leite pasteurizado e ensacado vindo das propriedades mineiras pesquisadas de baixa produtividade (preço de US $\$ 0,35$ o litro de leite frente a US $\$ 0,38 /$ itro, respectivamente. $^{12} \mathrm{O}$ estrato que apresentou maior vantagem, em termos de preço, foi o de alta produtividade, com US $\$ 0,29 /$ litro, sendo seguido pelo estrato de média produtividade, com US\$ 0,34/litro (Araújo, 1994).

Em um segundo momento, com a efetivação da integração dos mercados, seriam eliminadas as restrições tarifárias e não tarifárias, o que reduziria o custo de internalização do produto e o preço do leite em pó vindo do Mercosul. ${ }^{13}$ Segundo Araújo (1994), o valor do leite em pó reidratado e ensacado, eqüivaleria a US $\$ 0,28$ /litro $(\mathrm{CIF})$, o que certamente mudaria - o cenário descrito anteriormente, pois só o estrato de alta produtividade (com preço por litro de US $\$ 0,29$ ) estaria relativamente menos vulnerável.

Nestes termos, considerando que a análise de competitividade tomou por base uma amostra com melhor desempenho produtivo relativo, ${ }^{14}$ então, a

\footnotetext{
10

A autora considerou a Argentina como país representativo da região, por ter sido o que mais exportou para o Brasil, sendo que o preço praticado pela Argentina está atrelado ao mercado internacional.

${ }_{11}$ Neste primeiro momento a autora considerou os custos de produção relativos.

12 Reidratado e ensacado.

13 Nesta etapa a autora considerou os custos de internalização do leite.

14 As propriedades mineiras pesquisadas apresentam desempenho acima da média do Estado, e Minas Gerais é o principal produtor do pais
} 
internalização do leite em pó dos demais paises do Mercosul para o Brasil traz maiores preocupações com o setor, porque as demais regiōes e propriedades tendem a ser menos competitivas, podendo implicar em uma significativa perda de mercado por parte do produtor interno.

Outro resultado da pesquisa da autora que revela a perda de mercado descrita acima, diz respeito aos dados referentes ao Coeficiente de Proteção Nominal para os estratos de baixa, média e alta produtividades da atividade leiteira no Brasil. ${ }^{15}$ Os resultados apontam para uma indiferença por parte da indústria de laticínios em processar o produto nacional ou importado, comparando o leite produzido pelo estrato de alta produtividade e o leite vindo da Argentina, pois os preços relativos são quase os mesmos.

Mas a competitividade maior do leite argentino se faz sentir frente aos estratos de baixa e média produtividades, dado que os resultados nestes estratos indicam a existência de maiores preços relativos.

Como forma de reduzir os impactos negativos resultantes da internalização de leite em pó do Mercosul, Araújo (1994) indica como alternativa a busca por maior competitividade interna, via melhorias no nivel tecnológico empregado na atividade leiteira, redução da proteção à indústria doméstica de insumos e da tributação indireta, e difusão de sistemas eficientes, a fim de elevar a produtividade média do rebanho.

Contudo, apesar da importância desta consideração, há alguns aspectos que devem ser agregados na análise da busca por melhoria de competitividade interna, decorrente de uma maior abertura externa no futuro.

Primeiro, a oferta interna tem sido afetada negativamente por componentes estruturais internos (perfil da demanda final e intermediária, produção não especializada; risco institucional) e externos (políticas de estímulo a exportaçōes de excedentes por parte dos grandes produtores), o que, ao longo do tempo, contribuiu e ainda contribui para barrar a modernização do setor leiteiro como um todo no Brasil.

Assim, o que se prevê em termos de produção interna, é uma dificuldade no rompimento destas barreiras e um efetivo deslocamento de demanda, do produtor interno para o produtor estrangeiro, com a internalização de leite mais barato advindo dos paises do Mercosul, em um primeiro momento.

Segundo, deve-se considerar que, apesar de os produtores mais próximos do Brasil serem os ofertadores potenciais de leite e derivados, os mesmos não

\footnotetext{
15 Segundo Araujo (1994), os Coeficientes de Proteção Nominal (CPNs) são indicadores sumários da estrutura de incentivos relativos gerada por politicas especificas através do tempo, e são calculados por meio da razão entre preço doméstico intermediário pelo preço de internalização do produto. Se o CPN > 1, os produtores domésticos ou os intermediários recebem um preço maior que o preço de internalização do produto importado, e se CPN $<1$, ocorre o oposto Se o CPN = 1, os preços domésticos e do produto importado são iguais
} 
têm capacidade produtiva para suprir toda a demanda potencial brasileira por leite. Assim, se a produção de leite dos países do Mercosul não for suficiente para fazer face às importações brasileiras, então a importação de países de fora da comunidade econômica do Mercosul se tornaria indispensável com a efetivação da demanda. ${ }^{16}$

No que diz respeito à tarifa externa comum para importações de lácteos advindos de terceiros mercados, como mecanismo de proteção e de influência sobre a competitividade brasileira, o que se pode deduzir é que este dispositivo, que busca elevar o preço do produto estrangeiro, não seria suficiente frente à necessidade de complementação da disponibilidade interna, que é histórica.

\subsection{Mudanças no consumo e ajustes no setor leiteiro nos próximos anos}

Além da influência da integração dos mercados sobre o comércio regional de lácteos, é importante analisar quais os cenários com que a produção leiteira no Brasil irá se deparar, em função do que acontecer em termos de crescimento econômico e alterações no consumo.

De acordo com o nível que o crescimento econômico brasileiro atingir nos próximos anos, diferentes taxas de crescimento das demandas por produtos alimentares irão ocorrer. Desta forma, a produção agrícola teria que sofrer ajustes necessários para responder à maior demanda e para não depender de maiores volumes de produtos estrangeiros, o que se aplica inclusive ao setor leiteiro.

Já a alguns anos, estudos que vêm sendo realizados por Montoro et alii apud Homma (1991), Mello (1990) e Alves (1986) indicam que, dadas as variações futuras nas taxas de crescimento do PIB, no crescimento populacional e no padrão de consumo, teriam que ocorrer mudanças significativas no perfil agrícola como um todo, e, particularmente, no perfil produtivo do setor leiteiro brasileiro.

Montoro et alii apud Homma (1991) e Mello (1990) consideraram trajetórias alternativas de crescimento para a economia brasileira nos próximos anos, sendo que os resultados apontam para uma maior pressão da demanda sobre a oferta de leite no Brasil, ${ }^{17}$ resultante de um crescimento econômico nos anos 90.

\footnotetext{
${ }^{16}$ Mas, apesar da fração de mercado a ser abarcada pelos países produtores mais eficientes no Mercosul não suprir a demanda brasileira total, de qualquer forma, a entrada de produtos lácteos importados afeta a estrutura vigente no mercado leiteiro do Brasil. É importante considerar que a região Sul do Brasil, onde predomina a pequena produção de até 50 ha, è a que estaria mais exposta à concorrência, devido à sua maior proximidade com a Argentina e o Uruguai.

17 Dentre outros alimentos.
} 
Se o cenário de crescimento econômico for aquele que assume uma prática de distribuição de renda a favor de salários e de gastos sociais, incluindo aumento na taxa de investimentos, a taxa média de crescimento anual do PIB seria em torno de $6,5 \%$ (este seria denominado "cenário social", no qual haveria um crescimento com eqüidade). Neste caso, a demanda por leite no Brasil cresceria $7,26 \%$ ao ano, e a oferta teria que alcançar mais que o dobro da quantidade produzida atualmente, cerca de 33.190 milhões de litros de leite. ${ }^{18}$

Juntamente com os efeitos do crescimento econômico sobre a demanda por alimentos, surgiria o "efeito graduação no consumo", no caso do "cenário social". Este efeito se traduz em um incremento da classe média e a adoção, por parte dos novos integrantes, de hábitos alimentares típicos desta faixa de renda. Aqui, o resultado seria uma modificação no padrão alimentar, com um consumo maior, por exemplo, de proteinas animais, o que inclui o leite, dentre outros alimentos. Assim, o crescimento econômico traria consigo mudanças significativas dos hábitos alimentares no Brasil, o que forçaria um ajuste no perfil agrícola, não somente em termos quantitativos (aumento da quantidade ofertada), mas também em termos qualitativos (aumento da oferta interna de produtos de origem animal e vegetal em detrimento de produtos ricos em carboidratos).

Além da participação do crescimento econômico nas pressões de demanda, estes estudos indicam em que grau o crescimento populacional pode influenciar - movimento de maior demanda. A previsão é de declínio relativo no crescimento populacional nos anos 90 , em torno de $1,7 \%$ ao ano no primeiro qüinqüênio e $1,5 \%$ no segundo, o que significa menor pressão desta variável sobre o crescimento da demanda e sobre a oferta de alimentos, em relação à pressão exercida pelo crescimento econômico e o efeito graduação. Em suma, os resultados indicam que, dentre os produtos agrícolas analisados, a maior taxa prevista de crescimento do consumo é a do leite, indicando um grande desejo de realizar uma melhoria qualitativa nos hábitos de consumo.

Neste sentido, o grande desafio para o setor leiteiro no Brasil nos próximos anos seria atender à maior demanda, por meio de uma melhoria no seu desempenho produtivo. Caso contrário, a alternativa para solucionar os déficits de oferta tende a ser a importação do produto, alternativa também ponderada

\footnotetext{
18 Os autores consideraram, inciusive, dois outros cenários: o primeiro, status quo, sugere a continuidade, na próxima década, dos impasses na economia brasileira, provocando uma taxa de crescimento econômico relativamente baixa, em torno de 4 a $5 \%$ do PIB entre 1989 e 2.000 . Neste caso, a produção de leite teria que alcançar o patamar de 25.674 milhões de litros, para responder a uma demanda por leite com taxa de crescimento de $4,78 \%$ até o ano 2.000 Já o cenário "milagre" apresentaria um quadro de crescimento semelhante ao dos anos $70, \mathrm{com}$ um crescimento do PIB da ordem de $7 \%$ ao ano e, neste caso, para o atendimento da demanda por leite, que cresceria cerca de $6,37 \%$ no período, a produção teria que chegar a 30279 milhões de litros de leite
} 
por Fernandes (1989). Segundo este autor, se for feita uma redistribuição de renda, a produção de alimentos tem de aumentar abruptamente, e dificilmente a oferta terá condições de atender à demanda, o que poderá implicar em aumentos das importações.

\section{EFEITOS DAS IMPORTAÇÕES SOBRE O DESENVOLVIMENTO DA PECUÁRIA LEITEIRA NO BRASIL}

Somente a partir dos anos 80 é que a política de importação de alimentos, incluindo o leite, passou a ter maior importância relativa enquanto volume de recursos direcionados para tal fim, apesar de, historicamente, isto não representar um fato novo.

Desta forma, enquanto entre os anos 60 e 70 o volume de recursos destinados à importação de leite em pó no Brasil, foi de cerca de 195 milhões de dólares, somente nos anos 80 , estes recursos atingiram em torno de 705 milhões de dólares. Nos anos 90, esta tendência de crescentes gastos de recursos com importações de leite também se verificou, dado que somente em 4 anos (1990 a 1993), foram gastos cerca de 390 milhões de dólares com importações de leite (Tabela 1).

Este movimento não somente reflete a tendência crescente da importância das importações como elemento neutralizador da insuficiência da oferta interna de alimentos, mas também provoca distorções. Tendo em vista que essa política, de caráter conjuntural e oscilante, tem maior preocupação com o último elo da cadeia agroindustrial do leite, ou seja, a demanda, e, por extensão, com as repercussões de um não atendimento da mesma, deixa-se o produtor à mercê das instabilidades que a internalização de um produto substituto perfeito (leite em pó), muitas vezes subsidiado na origem, traz. 
Tabela 1 - Importação brasileira de leite em pó, 1960 A 1993

\begin{tabular}{|c|c|c|c|c|}
\hline & & Quantidade (t) & Valor em U\$1.000 & \\
\hline & 1960 & 3.950 & & 741 \\
\hline & 1961 & 10.600 & & 2.935 \\
\hline & 1962 & 12.540 & & 2.774 \\
\hline & 1963 & 19.030 & & 5.518 \\
\hline & 1964 & 19.088 & & 5.178 \\
\hline & 1965 & 21530 & & 6.802 \\
\hline & 1966 & 24.550 & & 10.329 \\
\hline & 1967 & 25.640 & & 12.368 \\
\hline & 1969 & 12.150 & & 6.673 \\
\hline & 1970 & 22.003 & & 13.510 \\
\hline & 1971 & 14.881. & & 10.831 \\
\hline & 1972 & 11.832 & & 8.233 \\
\hline & 1973 & 14.147 & & 11.196 \\
\hline & 1974 & 21.055 & & 22.706 \\
\hline & 1975 & 14.147 & & 11.596 \\
\hline & 1976 & 18.499 & & 11.801 \\
\hline & 1977 & 46.350 & & 28.194 \\
\hline & 1978 & 11.760 & & 11.582 \\
\hline & 1979 & 9.882 & & 10.849 \\
\hline & 1980 & 61.754 & & 73.408 \\
\hline & 1981 & 8.024 & & 20.316 \\
\hline & 1982 & 7.521 & & 17.255 \\
\hline & 1983 & 18.657 & & 23.630 \\
\hline & 1984 & 29.766 & & 16824 \\
\hline & 1985 & 31.007 & & 16.011 \\
\hline & 1986 & 214.071 & & 101.077 \\
\hline & 1987 & 101.077 & & 83.949 \\
\hline & 1988 & 4.517 & & 6.188 \\
\hline & 1989 & 105.011 & & 264200 \\
\hline & 1990 & 57.708 & & 105.198 \\
\hline & 1991 & 95.548 & & 147.558 \\
\hline & 1992 & 30.798 & & 57.159 \\
\hline & 1993 & 38.000 & & 70.000 \\
\hline
\end{tabular}

Fonte: FAO Trade Yearbook (1961 a 1993)

Estes prejuizos são evidentes pois os preços pagos aos produtores tem caído na medida em que são realizadas importações de leite. Desde outubro de 95 até janeiro de 96 , por exemplo, os preços pagos aos produtores têm caído cerca de $25 \%$ na região de São Paulo, tradicional produtora de leite tipo B e representativa de produtores que atuam de forma mais moderna na atividade. $^{19}$ Esta queda nos preços pagos foi atribuída à importação de 100 mil toneladas de leite em pó e 60 mil toneladas de leite longa vida e creme de leite, o que obrigou os produtores a reduzirem seus custos via redução de

\footnotetext{
19 Neste ponto, é importante considerar aqui que os efeitos das importações atingem mesmo aqueles produtores de leite que adotam estratégias competitivas, como a estratégia de esforço para atingir custos mais baixos, dentre as demais sugeridas por Porter (1986)
} 
gastos com ração em plena safra. Em vista disso, a produção e a oferta ficaram aquém da cota, o que provocou redução de preços pagos aos produtores (Importação provoca queda..., 1995).

Neste contexto, percebe-se que as importações de produtos alimentícios em geral, afetam negativamente a produção agrícola $e$, no Brasil, normalmente ocorrem em função de quebra da safra interna, preços mais competitivos no mercado internacional, ou devido a aumentos repentinos no poder de compra da população.

A análise dos efeitos sobre a atividade leiteira interna, gerados pelas contínuas importações de leite, encontra respaldo em estudo acerca dos impactos setoriais de mudanças na demanda final da agricultura, realizado por Vasconcelos (1992).

Segundo os resultados deste estudo, das atividades desmembradas do setor agricola na matriz de insumo-produto, a atividade leiteira está entre as atividades agrícolas que apresentam os maiores multiplicadores do produto, renda e emprego, $2,5040,1,6024$ e 13,3910, respectivamente. Isto significa que a atividade leiteira tende a responder, a nível de produção, renda e emprego com significativa intensidade, a qualquer variação em suas demandas finais.

Assim, por exemplo, a importação de cerca de 214.071 toneladas de leite em pó em 1986 (que pode ser considerada uma variação negativa na demanda final do setor), com um gasto equivalente de 183,887 milhões de dólares, corresponderia ao não direcionamento destes recursos para a atividade leiteira interna. Em termos de multiplicador do produto, isto significa que se estaria deixando de aumentar a produção interna em torno de 536.033.784 litros de leite (ou 536.034 toneladas de leite em pó, aproximadamente), que, em relação à produção do mesmo ano (cerca de 12,5 bilhões de litros), corresponde a $4,3 \%$ do total. Em termos regionais, este volume é superior ao total produzido pela maioria dos estados do País atualmente (Anuário Estatístico do Brasil, 1993).

Percebe-se ainda, que, o crescimento minimo previsto da demanda por leite até o ano $2.000,{ }^{20}$ eqüivale a uma pressão anual sobre a oferta de leite $(4,78 \%)$ num percentual próximo ao referente à produção que se deixou de realizar internamente, com as importações em 1986 (4,3\%). Esta projeção da magnitude de recursos que deixaram de ser direcionados para a atividade interna nos dá não só a idéia da intensidade com que as importações de leite no Brasil têm deixado de estimular o desenvolvimento do setor, mas do quanto pode vir a deixar de estimular, no caso de maiores pressões de demanda.

\footnotetext{
${ }^{20}$ O termo minimo diz respeito às taxas de crescimento da demanda por produtos agricolas de acordo com os cenários previstos no item anterior para o crescimento da economia. A demanda brasileira por leite pode variar entre $4,78 \%$ (cenário status quo), $6,37 \%$ (cenário milagre) e $7,26 \%$ (cenário social) ao ano.
} 
Em termos de efeitos sobre a renda, os gastos com importação de leite em pó, deixaram de gerar renda no montante de cerca de 362 milhões de dólares em 1986. Por outro lado, deixou-se de criar, internamente, cerca de 402 mil empregos diretos e indiretos com as importações de leite em 1986.

Seguindo o mesmo raciocinio anterior, se houvesse a definição de uma política agrícola que direcionasse o montante de recursos gastos com importação de alimentos, ${ }^{21}$ dentre os quais se encontra o leite, para os setores leiteiros de regiões pouco produtivas, que são regiões pauperizadas frente às do Centro-Sul do país, ter-se-iam, então, maiores incentivos ao desenvolvimento do setor leiteiro no Brasil como um todo e ao emprego de mão-de-obra na atividade. ${ }^{22}$ Além disso, uma política de importação de leite, além de não gerar demanda na própria atividade leiteira, também deixa de irradiar efeitos positivos de outras atividades, podendo-se, portanto, afirmar que variações negativas na demanda por leite afetam outros segmentos do complexo agrícola do País. ${ }^{23}$

Por sua vez, os efeitos da redução na demanda final por produtos derivados de leite sobre a aquisição da matéria-prima do setor leiteiro são ainda maiores. Isto porque para cada uma unidade monetária que se deixa de realizar domesticamente em termos de demanda por derivados lácteos, a indústria laticinista deixa de comprar da produção interna de leite, 0,6365 unidades monetárias. $E$, dado que o multiplicador do produto para a indústria de laticinios é de 3,1159 , isto significa que, o próprio setor laticinista deixa de gerar um produto no valor de cerca de 3,12 unidades monetárias, para cada unidade importada de derivados lácteos (Vasconcelos, 1992).

Assim, a análise dos efeitos das importações de leite sobre o setor interno, revela como a demanda por importação de lácteos não contribui para o rompimento do relativo atraso na estrutura produtiva interna, e, caso se

21 Estes impactos obviamente são maiores, na medida em que também são significativas as importações de outros produtos derivados lácteos, além do leite em pó, como queijo, manteiga e sobremesas lácteas (Lopes e Jank, 1992)

22 E evidente que este movimento pressupõe a atuação conjunta de políticas regionais e macroeconômicas efetivas na resolução de problemas históricos, que estabelecessem vinculos mais sólidos do produtor rural na atividade, como a reforma agrária, programas contra a estiagem prolongada e 0 analfabetismo, dentre os muitos existentes. Em nenhum momento se adota 0 pressuposto de que basta somente redirecionar recursos para que a atividade se desenvolva.

${ }^{23} \mathrm{O}$ impacto da realização de importações de leite ocorre também sobre outros setores que se interrelacionam com o setor leiteiro, principalmente sobre a produção de soja, milho, adubos e rações, produtos que entram como insumos diretos na atividade leiteira (como o farelo de soja e de trigo e rações), ou que são responsáveis na produção destes insumos (como os adubos). Então, por exemplo, caso se deixe de realizar uma demanda final de uma unidade monetária por leite, isto significa que não estão sendo demandados internamente produtos como soja, milho, adubos e rações, no montante de $0,025,0,032,0,15$ e 0,191 unidades monetárias, respectivamente (Vasconcelos, 1992) 
perpetue a política de importação de leite e derivados, este atraso tende a ser maior.

Percebe-se, então, que as politicas de importação de leite no Brasil deixaram de estimular o produtor nacional e valorizaram o produto importado, pois incentivou-se a produção estrangeira, na medida em que também foram concedidas isenções de tarifas, mesmo quando o produto estrangeiro era beneficiado com subsidios na origem (Jank, 1993).

\section{CONSIDERAÇÕES FINAIS}

A partir das informações acerca dos aspectos que caracterizam a produção de leite em diversos países, pode-se constatar que o setor se revela bem estruturado tecnologicamente em boa parte deles, contrastando com o perfil produtivo do Brasil. Pois, conforme mencionado, no Brasil, a oferta tem sido insuficiente em termos de disponibilidade por habitante, nos padrões da Organização Mundial de Saúde, e não tem havido mudanças no sentido de modernizar sua estrutura produtiva como um todo e alcançar maiores niveis de produtividade.

Por outro lado, agentes como o consumidor final, o governo e as indústrias laticinistas, apesar de fundamentais na evolução e no desenvolvimento de todo o complexo agroindustrial do leite, não propagaram as influências necessárias à efetivação desta modernização dos produtores em geral.

Como resultado do perfil produtivo interno, tem ocorrido a internalização de produtos importados do Mercosul, dos EUA e da CEE a preços competitivos, e até subsidiados na origem, fato que vem contribuir como um aspecto a mais na exacerbação dos entraves ao desenvolvimento do setor leiteiro no Brasil. Neste contexto, as chances de mudanças no perfil produtivo desta atividade parecem remotas.

Deste modo, dos fatores que influenciam o processo de importações de leite no Brasil, o padrão da atividade leiteira interna apresenta-se como grande responsável, pois não produz a niveis compativeis com as necessidades da população, o que acaba revelando a tendência de continuidade das importações de lácteos no Brasil para os próximos anos.

Entretanto, pode-se dizer que, atualmente, a proposta de exposição à produtos importados como meio de aumentar a oferta interna se revela, em geral, senso comum. Mas esta proposta parece não considerar a possibilidade de se cair em um círculo vicioso, nem as peculiaridades do setor rural.

Esta proposta parede não considerar, além dos fatores estruturais, outros fatores que tendem a agir sobre este fluxo no futuro, como: a evolução das políticas agrícolas dos paises maiores produtores, que são capazes de influenciar não só os preços mundiais de lácteos, mas também de influenciar a 
absorção de seus excedentes, por meio de mecanismos como subsídios à exportação; a integração do Mercosul, que tende a eliminar tarifas aduaneiras para os paises integrados e reduzir o preço do produto lácteo importado; a perspectiva de crescimento econômico interno com aumentos de renda real per capita, que define novos padrões de consumo, como a substituição de produtos ricos em carboidratos por produtos ricos em fibras e proteínas, de origem animal e vegetal.

Além destas premissas, a busca por maior oferta interna de leite deveria incluir a necessidade de se realizar melhorias no atual padrão de distribuição de renda, dado o reduzido poder de compra da maioria da população, como um dos fatores limitantes à expansão do setor.

Por outro lado, deveria considerar também que o desenvolvimento heterogêneo dos segmentos que compõem o complexo agroindustrial de leite e derivados - segmento fluido menos rentável e segmento de derivados mais dinâmico e lucrativo - tem sua parcela de contribuição na falta de estímulos, por parte da demanda, ao aumento da oferta de leite no Brasil.

Caberia, fundamentalmente, aos elos mais estruturados do complexo leiteiro, repassar os estímulos à modernização do produtor de leite, a exemplo do que é feito no Uruguai e Argentina.

Não se pode deixar de realçar também a necessidade de mudanças no sistema tributário, que possibilitassem reduções no custo de produção de leite, além de menores oscilações nas políticas de crédito e preços mínimos, que reduzissem o custo institucional.

Neste sentido, estímulos externos, como elevação dos preços mundiais decorrentes de menor protecionismo agricola mundial, precisam estar conjugados com outros estimulos internos.

Entretanto, não se tem perspectiva de implementação de políticas de longo prazo que possibilitem o desenvolvimento homogêneo do setor leiteiro no Brasil, pois o Estado tende a ter uma nova relação com a economia atualmente, dadas as suas politicas menos intervencionistas e mais controladas em termos de gastos públicos.

Em outros termos, isto significa que mudanças capazes de fortalecer e tornar o setor leiteiro no Brasil auto-suficiente são necessárias, mas não se visualiza nenhuma prioridade alimentar na definição das politicas agricolas atuais no Brasil, capazes de promover o desenvolvimento do setor.

Em suma, há aqui uma visão pessimista em torno da capacidade de resposta do setor leiteiro, centrada no grande número de variáveis que obstacularizam seu desenvolvimento e no fato de haver excedentes produtivos e estoques mundiais passiveis de serem absorvidos, em parte, pela demanda brasileira que possa vir a se efetivar. 
Por último, propor controle das importações de alimentos em geral e de leite em particular, pode parecer um contracenso na medida em que os paradigmas adotados atualmente propõem maior abertura econômica dos setores externos. Mas é preciso considerar que se os países hoje desenvolvidos não praticam na integra as sugestões propostas mundialmente, porque países em desenvolvimento, com setores agrícolas debilitados, o fariam de forma inquestionável?

Se a preocupação no direcionamento das políticas macroeconômicas e agrícolas continuar sendo a de busca de estabilidade econômica a qualquer custo, então, esta interrogativa perde sustentação. Mas não pode-se dizer o mesmo, caso haja uma meta e um compromisso com uma maior autosuficiência alimentar no longo prazo.

\section{BIBLIOGRAFIA}

ABREU, M. P. \& LOYO, E.H.M.M. A estrutura do comércio agricola mundial fundamentos dos interesses liberais e protecionistas. In: FAGUNDES, M.H. (org) Politicas agricolas e 0 comércio mundial. Estudos de Politica Agricola, n.28. Brasília: IPEA, 1994, p.47-86.

ALVES, E. Crescimento da demanda e da oferta de produtos agricolas nos próximos dez anos Analise e Conjuntura Belo Horizonte, n. 1, vol 1, p 53-65, jan./abr. 1986.

FIBGE. Anuário Estatística do Brasil, Rio de Janeiro FIBGE, 1993, v. 51.

ARAÚJO, C M. M. Competitividade de diferentes sistemas de produção de leite em Minas Gerais frente ao MERCOSUL. Viçosa: Universidade Federal de Viçosa, 1994. (Dissertação de Mestrado em Economia Rural)

BEASLEY, S. \& NEFF, S. CEE: os problemas de uma superpotência leiteira. Leite $B$. São Paulo: ABPLB, n.72, p. 34-38, out. 1992.

BECKER, T. C A política agricola comum da Comunidade Econômica Européia. In: FAGUNDES, M.H. (org) Politicas agricolas e o comércio mundial. Brasilia IPEA, 1994.

BOCHER, L.W. Os cães de guarda do leite americano. Leite B. São Paulo: ABPLB, n. 79, pg. 18-22, mai. 1993

BORTOLETO, E.E. \& WEDEKIN, VS.P. Pecuária leiteira no Brasil: análise e perspectivas. Informações Econômicas São Paulo: IEA, v. 20, n.7, jul.1990.

BORTOLETO, E. E. Mercado mundial de leite e derivados: uma apreciação no período 198492. Informações Económicas: São Paulo: IEA, v.22, n.5, p. 49-56, mai.1992.

BURTIN, J. A politica agricola comum e sua reforma. Luxemburgo. Publicações Oficiais da Comunidade Européia, 1988.

CARFANTAN, J.Y. As instituições e os recursos da Comunidade Europeia. Brasília: Companhia de Financiamento da Produção - CFP, Documento 1, 1993a.

CARFANTAN, J.Y. A Politica Agrícola Comum. Brasilia: Companhia de Financiamento da Produção - CFP, Documento 2, 1993b.

CARLEY, D. A maioria dos paises ricos protege o seu leite. Leite $B$. São Paulo: ABPLB, $n$. 75, p. $18-20$, jan. 1993.

COUTINHO, P. C. (coord.) O impacto de políticas de suporte à agricultura sobre a economia Brasileira: uma proposta de quantificação. Estudos de Política Agrícola Relatório de Pesquisas, n. 29. Brasilia: IPEA, 1994

DIAS, J.C. O leite no Cone-Sul: Argentina, Uruguai e Chile Leite B. São Paulo: ABPLB, n.50, 
p. 12-50, dez. 1990

DIAS, J.C. Nem só de turismo e laranja vive a Flórida. Leite $B$. São Paulo: ABPLB, n.73, p. 2629, nov 1992

DIAS, J.C As dez maiores do leite Leite B. São Paulo ABPLB, n 75, p. 12-34, jan. 1993

ESTATISTICAS LÁCTEAS Leite B, São Paulo: ABPLB, n.36, p. 6-7, julho/1989.

FAO. Production Yearbook. Roma: Coleción Estadistica, 1993

Trade Yearbook. Roma: Coleción Estadistica, de 1960 a 1993.

El Estado Mundial de la Agricultura y la Alimentación. Roma: Organización de las Naciones Unidas para la Agricultura y la Alimentación, Colección FAO: Agricultura, n.27, 1994

FARINA, E.M.M.Q. Política pública e evolução recente da pecuária leiteira no Brasil. In: DELGADO, GC et alii. Agricultura e políticas públicas Brasilia IPEA, 1990.

FERNANDES, C. L. L Impactos de mudanças no padrão de distribuição de renda sobre emprego, produto e outras variáveis macroeconômicas: um estudo de caso para a economia brasileira. Revista Brasileira de Economia, Rio de Janeiro, v.43, n.3., p. 393412 , jul/set. 1989

GOMES, S.T. et alii. O custo de produção de leite. Brasilia: SNAB/MA, 1989.

HOMMA, A.KO Será possivel a agricultura auto-sustentada na Amazônia? IN TEIXEIRA, E C. (org). A politica agrícola da década de 90. Viçosa: Imprensa Universitária/UFV, 1991.

IMPORTAÇÃO PROVOCA queda dos preços e gera crise em São Paulo. Folha de Săo Paulo, p. 3, agrofolha, 23/01/96.

JANK, M. S. A importáncia do setor agroindustrial na integraçăo do Cone Sul: as cadeias mais sensiveis. Piracicaba: Instituto de Estudos Avançados, 1992.

JANK, M.S. O Brasil faz tudo errado no leite. Leite B. São Paulo: ABPLB, n.76, p. 8-12, fev. 1993.

LANGLEY, S.V. A política agricola norte-americana In FAGUNDES, M. H. (org). Politicas agrícolas e o comércio mundial. Brasilia: IPEA, 1994.

LOPES, M.R. \& JANK, M.S. Caracterização do setor lácteo da Argentina: algumas comparações com o Brasil (relatório final). São Paulo ABPLB, dez 1992.

MARTINS, R.S. Análise da politica de preço do leite no Brasil, 1960-87, Viçosa: Universidade Federal de Viçosa, 1992. (Dissertação de Mestrado em Economia Rural).

MASCOLO, J.L. Um estudo econométrico da pecuária de corte no Brasil. Rio de Janeiro. Fundação Getülio Vargas, 1980

MELLO, F. H. O crescimento agricola brasileiro dos anos 80 e as perspectivas para os anos 90 . Revista de Economia Politica, v. 10, n. 3 (39), p. 22-30, jul/set. 1990.

MENDES, C.M. Estudo da demanda brasileira por leite e derivados no período de 1970-87. Viçosa: Universidade Federal de Viçosa, 1990. (Dissertação de Mestrado em Economia Rural).

MUELLER, C. C O ciclo do gado e as tentativas governamentais de controle do preço da carne Estudos Económicos. São Paulo, v. 17, n. 3, p. 436-456, set/dez. 1987.

PIANAZZA, L.A. \& MOURA, LC O que foi feito do ciclo da pecuária. Agroanalysis Fundação Getúlio Vargas, v. 16, n.4, p. 21-26, abril 1996.

PORTER, M.E. Estratégia competitiva técnicas para análise de industrias e da concorrência. Rio de Janeiro: Campus, 1986.

REIS, R.P. et alii. O mercado de leite: política de intervenção e estrutura produtiva. Revista de Economia e Sociologia Rural. Brasilia, v. 31, n. 3, p 215-229, jul./set 1993.

REZENDE, G. C. Setor externo e agricultura. Literatura Económica. Rio de Janeiro: Instituto de Planejamento Econômico e Social, n 5, v 3, p. 299-316, 1983.

SILVA, I. M da. Liberação dos preços de leite reflexos e perspectivas Informaçđes 
Económicas. São Paulo, v. 23, n. 2, p 9-21, fev. 1993

SOARES, P. Empresa argentina aposta na segmentação. Gazeta mercantil, 5 de janeiro de 1995.

TUBIANA, L. O comércio mundial dos produtos agrícolas: da regulação global ao fracionamento dos mercados. Ensaios FEE. Porto Alegre: FEE, n.6 v 2, p. 103-126, 1985

VASCONCELOS, C.F. Impactos setoriais de mudanças na demanda final sobre o desempenho da agricultura. Viçosa: Universidade Federal de Viçosa, 1992. (Dissertação de Mestrado em Economia Rural).

ZYLBERSZTAJN, D. \& FARINA, EM.M.Q. A questão da agroindústria. São Paulo: Instituto de Estudos Avançados, 1991.

ABSTRACT
MILK IMPORTS AND THE IMPACTS ON
THE DEVELOPMENT OF THE DAIRY SECTOR IN BRAZIL
Milk supply has been growing insufficiently, inducing to constant imports of dairy
products, which are several times subsidized in their origin, as a way of minimizing the
crisis of internal provision in critical periods. These imports being about a new concern
with the development of the dairy sector, since they discourage the producers in their
decision to increase production and adopt technology. In this context, this study had the
objective to evaluate the possible factors that influence or determine the import flows of
milk and the effects on the dairy sector in Brazil, in the domestic and international
contexts.

